\title{
Behavior-driven agent-based models of spatial systems
}

\author{
Xinyue Ye $^{1} \cdot$ Yuri Mansury ${ }^{2}$
}

Received: 28 September 2016 / Accepted: 28 September 2016 / Published online: 8 November 2016 (C) The Author(s) 2016. This article is published with open access at Springerlink.com

\begin{abstract}
Human behavior can produce complex patterns in spatial systems made up of large numbers of interacting individuals. An inquiry into the nature of spatial patterns is therefore incomplete without an understanding of the human behavior that gives rise to these patterns (Xie et al. in Ann Assoc Am Geogr 97(3):477-495, 2007). The treatment of pattern formation in space with interacting individuals, however, is tremendously difficult using purely mathematical abstractions. This special issue is an effort to promote new behavioral approaches to the class of computational platforms known as agent-based models.
\end{abstract}

JEL Classification R1 General Regional Economics · C63 Computational Techniques; Simulation Modeling · D010 Microeconomic Behavior; Underlying Principles

Computational agent-based models (ABMs) since inception have been recognized as a powerful tool to help understand the behavior of complex spatial systems (Batty 2007). This class of models is "agent based" because it seeks to explain emerging spatial orders (the systems behavior) in terms of local interactions among decisionmakers (agents) as well as between them and the environment. Cities and regions are quintessential examples of complex systems made up of interacting agents from

\footnotetext{
$凶 \quad$ Yuri Mansury

ymansury@iit.edu

Xinyue Ye

xye5@kent.edu

1 Department of Geography, Kent State University, Kent, OH 44240, USA

2 Department of Social Sciences, Illinois Institute of Technology, Chicago, IL 60616, USA
} 
a great many backgrounds. ABM enable regional scientists to deconstruct territorial patterns while preserving the integrity of the broader community and the behavior of its constituents.

Agents make decisions-from where to live and work to what to consume and produce-autonomously according to their present condition, past history, state of the local environment, and rules governing their actions (Ye and Lee 2016). There is a growing recognition of the importance of spatial dynamic relationships in explaining spatial-social processes. Spatial turn has been noted in many socioeconomic theories, which has yielded significant insights into social sciences and humanities. This special issue focuses on spatial ABM where the connection between settlement patterns and location decisions is explicit. At the same time, computer simulations provide a path for overcoming the analytical intractability that discreteness, nonlinear dynamics, and spatial dependencies bring about. Models of geographic systems indeed often lack the sweeping generality characteristics of the non-spatial counterparts. Simulations provide a quantum improvement in addressing the analytical intractability of geographical landscapes.

ABM have transformed how we model the tension between the individuals and the society lurking beneath spatial patterns (Conte and Giardini 2016). Despite the growing use for geospatial modeling in many areas of science due to the recognition of the spatial dimension in the socioeconomic phenomena, ABM have remained on the fringe of mainstream regional science due to the perceived lack of microfoundationsthe individual-level motivations that lead to the emergence of spatial orders. A growing body of empirical behavioral studies suggests that individual decisions are driven by optimization and satisficing goals. Millions of urban dwellers, for example, organize themselves into cities that evolve because of their pursuit for a better life.

There is also ample evidence that people act on the basis of limited information, peer pressure, and political constraints (Bonabeau 2002). The return of irrational exuberance in the housing market despite huge setbacks not so long ago illustrates the disparity between our gut feelings and the overwhelming evidence to the contrary. These facts have led to highly topical subjects for intellectual inquiry and have long been the interest of policy initiatives. Microfoundations here are more broadly defined, encompassing cognitive, social, and political factors that drive agent behavior, while not ignoring the powerful influence of self-interested rationalities. If there are indeed microfoundations for complexity in space, then we should find a way to embed them in our ABM. Consider, for example, the recent eruptions of spontaneous protests against the implicit bias of law and order officials. How does the behavior of select groups of citizens lead to mass riots and how can we account for them in our model of urban political dynamics?

An instrumental building block for a robust microfounded agent-based model is thus the specification of how the agents behave. Choosing the right set of decision rules is crucial in understanding the emergent properties of interacting agents in intricate systems where intuition fails. While complex systems are full of surprises, being able to articulate the microbehavior that crystallizes into macro-patterns goes a long way toward extracting the causal relations that bind a spatial system and its constituents. Despite the potentially significant efforts involved, the stakes have never been higher. Massive and sudden transformations of socioeconomic structures worldwide, which 
are responsible for the geographic patterns of growth and decline, all point to the increasing importance of individual behavior and human adaptability.

The mainstream's reluctance to embrace agent-based modeling has prompted the need for behavioral-driven models that are consistent with the microevidence on individual decisions. As one response, this special issue of The Annals of Regional Science is devoted to state-of-the-art analyses employing spatial agent-based models that are built on solid microfoundations. The first paper in the special issue by Cho, Mansury, and Ye develops a spatially explicit dynamic agent-based model of social network formation. The dynamic agent interaction leads to the emergence of spatiotemporal heterogeneity of agent distribution. The paper by Torrens proposes to bridge the gap between individual behavior and regional outcomes by the use of simulation. In Torrens' model, each agent has an in-depth behavioral understanding of its environments and context. Further exploring the importance of context, Duinen, Filatova, Jager, and Veen investigate how farmers' irrigation adoption is shaped or reshaped by social networks and behavioral rules when facing drought risk. The authors propose a spatial economic $\mathrm{ABM}$ to simulate how droughts affect crop production, farm income, and farm decision-making. Moving to the urban context, Anantsuksomsri and Tontisirin develop a theoretical framework to examine traffic congestion from a microbehavioral perspective. The authors specify a game theoretical framework which offers a foundation to analyze the collective strategic decisions about the use of a common resource. The paper by Leeuwen and Lijesen proposes to integrate the merits of game theory and agent-based modeling. They argue that it is novel and feasible to apply agent-based modeling in the context of a multistage game. The final paper by Wang and Baddeley employs behavior-driven cellular automata to explore the seminal Coase theorem. The authors examine how urban infrastructure provision can be used to increase urban land values.

Developing behavior-driven agent-based models is a transdisciplinary research field for understanding and analyzing dynamic patterns, relationships, and changes of spatial systems where human activities and behaviors occur and evolve. The empirical observations in the special issue lend support to the notion that well-defined microfoundations are the basis of robust agent-based modeling. Meanwhile, ABM is increasingly being supported by the emergence of advanced simulation methods and visualization power, which have also motivated, if not directly provoked, new queries on socioeconomic theories. Many burgeoning efforts interface ABM with the open source revolution, seeking the cross-fertilization between the two fast-growing communities: users and open source developers (such as Netlogo) (Rey and Ye 2010). Open source represents a paradigm shift in geospatial research that has facilitated collaboration across disciplines.

As Rey (2009) suggests, "increased adoption of open source practices... can enhance the development of the next generation of tools and the wider practice of scientific research and education.... a tenet of the free software (open source) movement is that because source code is fundamental to the development of the field of computer science, having freely available source code is a necessity for the innovation and progress of the field." This user-led innovation in the open source ABM movement is also the philosophy of conducting research. Further research on integrating space into formal theoretical models of behavior-driven agent-based models as well as on 
developing the next generation of analytical methods and software packages is needed to implement those models as the preconditions for reliable policy recommendations (Mansury and Gulyás 2007; Wilensky and Rand 2015).

Acknowledgments This research was funded by the National Science Foundation (1416509, ACI1535031, 1535081). We would like to thank Editor Professor Janet Kohlhase for her support and suggestions.

Open Access This article is distributed under the terms of the Creative Commons Attribution 4.0 International License (http://creativecommons.org/licenses/by/4.0/), which permits unrestricted use, distribution, and reproduction in any medium, provided you give appropriate credit to the original author(s) and the source, provide a link to the Creative Commons license, and indicate if changes were made.

\section{References}

Batty M (2007) Cities and complexity: understanding cities with cellular automata, agent-based models, and fractals. The MIT Press, London

Bonabeau E (2002) Agent-based modeling: methods and techniques for simulating human systems. Proc Nat Acad Sci 99(suppl 3):7280-7287

Conte R, Giardini F (2016) Towards Computational and Behavioral Social Science. Eur Psychol 21(2):131140. doi:10.1027/1016-9040/a000257

Mansury Y, Gulyás L (2007) The emergence of Zipf's Law in a system of cities: an agent-based simulation approach. J Econ Dyn Control 31(7):2438-2460

Rey SJ (2009) Show me the code: spatial analysis and open source. J Geogr Syst 11:191-207

Rey SJ, Ye X (2010) Comparative spatial dynamics of regional systems. In: P'aez A, Gallo JL, Buliung R, Dall'Erba S (eds) Progress in spatial analysis: methods and applications. Springer, Berlin, pp 441-463

Wilensky U, Rand W (2015) An introduction to agent-based modeling: modeling natural, social, and engineered complex systems with NetLogo. MIT Press, London

Xie Y, Batty M, Zhao K (2007) Simulating emergent urban form using agent-based modeling: Desakota in the Suzhou-Wuxian region in China. Ann Assoc Am Geogr 97(3):477-495

Ye X, Lee J (2016) Integrating geographic activity space and social network space to promote healthy lifestyles. ACM SIGSPATIAL Health GIS News1 8(1):24-33 